\title{
Stock Returns And Volatility İn An Emerging Equity Market. Evidence From Kenya
}

\author{
David Ndwiga, MA \\ Peter W Muriu, PhD \\ School of Economics, University of Nairobi
}

doi: 10.19044/esj.2016.v12n4p79 URL:http://dx.doi.org/10.19044/esj.2016.v12n4p79

\begin{abstract}
This study investigates volatility pattern of Kenyan stock market based on time series data which consists of daily closing prices of NSE Index for the period $2^{\text {nd }}$ January 2001 to $31^{\text {st }}$ December 2014. The analysis has been done using both symmetric and asymmetric Generalized Autoregressive Conditional Heteroscedastic (GARCH) models. The study provides evidence for the existence of a positive and significant risk premium. Moreover, volatility shocks on daily returns at the stock market are transitory. We do not find any significant leverage effect. Introduction of the new regulations on foreign investors with a $25 \%$ minimum reserve of the issued share capital going to local investors (in 2002), introduction of live trading, cross listing in Uganda and Tanzania stock exchange (in 2006) and change in equity settlement cycle from $\mathrm{T}+4$ to $\mathrm{T}+3$ (in 2011) significantly reduce volatility clustering. The onset of US tapering increase the daily mean returns significantly while reducing conditional volatility.
\end{abstract}

Keywords: Conditional volatility, GARCH models and leverage effect

\section{Introduction}

Why stock returns change over time still remains a puzzle ever since its first documentation by Schwert (1989). Emerging markets' stock returns portray at least four distinguishing features; high sample average returns, low correlations with developed markets' returns, more predictable returns and higher volatility (Bekaert and $\mathrm{Wu}, 2000$ ).

When stock price variability reaches extreme levels, the consequences can be adverse. First, if such volatility persists, firms are less able to use their available capital efficiently because of the need to reserve a larger percentage of cash-equivalent investments in order to re-assure lenders and regulators. Second, such volatility increases market-making risks and requires market intermediaries to charge more for their liquidity services, 
thereby reducing the liquidity of the market as a whole. Third, high volatility discourages investors from holding stock given that the expected returns have to be traded off for the risk exposure thus leading to demand for high risk premium to leverage volatility risks (Black and Scholes, 1973).

There is vast empirical literature on volatility of stock returns but with a focus on the developed markets. What holds in the developed markets, may not necessarily hold for the emerging markets. Existing literature shows mixed results, contradictory and also convergence in some studies. A number of studies show that stock returns portray asymmetric conditional volatility overtime with negative shocks having a higher impact on volatility compared to positive shock of the same magnitude (See for example Rafagut and Afzal 2012; Goudazi and Ramamarayan 2011 and Chiang and Doong 2001). This is inconsistent with Rousan and Al-Khaouri (2005). Whereas some studies finds evidence of long memory hence possibilities of predicting future volatilities (Maheshchandra 2012, Cifter, A. \& Ozun, A. (2008), Mcmillan and Thupayagale 2008, Kasman and Torun 2007 and Bannerje and Sakar 2006), others report no long memory (Kormaz et al 2009a, Kilic 2004). The evidence therefore remains inconclusive.

Evidence on stock returns volatility at the Nairobi Stock Exchange (NSE) is also scant. Using monthly data, Oluoch and Oyugi (2012) investigated the market risk (beta) using the Capital Asset Pricing Model (CAPM) for different market segments at the NSE. They conclude that various equity investments segments of NSE exhibit unique idiosyncratic factors that influence segmental market risk. The study however fails to characterize the nature of volatility perhaps due to the weaknesses of CAPM in explaining stock returns. Their study was also conducted during the postelection violence of 2007/2008 and the global financial crisis which may have impacted on the findings.

The aim of this paper was to investigate the dynamics in stock returns volatility at NSE for the period 2001-2014. The choice of this period was informed by various reforms that have been undertaken at the bourse. These includes a rise in initial public offers (IPOs), additional offers (AOs), right issues, bonus issues and stock splits all of which have great influence on stock returns. Moreover, cross listing, demutualization, dematerialization and global financial crisis occurred in this period which is likely to influence returns' volatility. With the upward surge of the NSE index and bullish behaviour dominating the market to the end of 2013, an empirical scrutiny is therefore worthwhile and timely. There have also been concerns over the impact of fed tapering announcements on emerging markets.

Volatility disrupts smooth functioning of security market by reducing investors' confidence. In the recent years, NSE has recorded an upward surge in the market returns with the stock market index hitting a high of 4970 
points as at the end of October 2013 from 4133 points in December 2012 thus outperforming the Dow Jones industrial average in this period. Market capitalization rose to Ksh 1.8 trillion by the end of October 2013 from Ksh1.3 trillion in December 2012, a 41\% increase rising further to Ksh 2trillion in March $2014^{1}$.In spite of this growth, stock prices remained volatile between year 2001 and the first quarter of 2014 with bullish trends dominating 2010-2013 period.

In an attempt to enhance market efficiency, Capital Markets Authority (CMA) has spearheaded market diversification initiatives aimed at creating conducive environment for investments. These include; establishment of hybrid over the counter (OTC) bond market, formal OTC equity market and market segment for Small and Medium EnterprisesGrowth Enterprise Market Segment (GEMs). These reforms are also likely to have impacted on stock market volatility.

The current U.S tapering has seen the federal treasuries' interest rates rise by over 100 basis points following the reversal of monetary easing thus triggering capital outflows from emerging market. Since foreign investors dominate the NSE activities, U.S tapering is expected to affect volatility at NSE as investors liquidate their holdings in favour of U.S federal treasuries ${ }^{2}$.

Many questions regarding stock market volatility at NSE therefore remain unanswered. In particular, the following four pressing issues should receive more attention: First, does stock return volatility have long term impact? Second, is there asymmetric volatility in the Kenyan stock market? Third, what is the relationship between risk and return? Finally, to what extent has US tapering heightened volatility on stock returns? This study seeks to fill this research gap

This study makes three main contributions to the existing literature and policy. First, evidence on stock market volatility in Kenya is scant. In our endeavour to fill this research gap, we used the most recent high frequency daily data series covering the period 2001 to 2014. This enabled

\footnotetext{
${ }^{1}$ See https://www.nse.co.ke/

${ }^{2}$ The action by the U.S federal government to adopt monetary tightening in attempt to build up on their reserves by reducing the size of bond buying programme after the global financial crisis. In December 2013 the government decided to taper its quantitative easing policy from $\$ 75$ to $\$ 85$ billion per month. The consensus is that tapering will continue through 2014 and wind up by the end of 2014.Beginning in February 2014, the federal committee agreed to add holdings of agency mortgage-backed securities at a pace of $\$ 30$ billion per month rather than $\$ 35$ billion per month, as well as adding to its holdings of longer-term Treasury securities at a pace of \$35 billion per month rather than $\$ 40$ billion per month. This is expected to lead to massive outflow of capital from emerging markets with South Africa already experiencing the effects as evidenced in deterioration of the Rand's value.
} 
us to capture the reforms undertaken at NSE for a period of 14 years. More importantly was the recent 2013/2014 U.S tapering effects.

On the policy front, understanding dynamics of stock return volatility will guide Capital Market Authority in developing measures that would dampen price volatility. Policy makers mainly rely on market estimates of volatility as a barometer of the vulnerability of financial markets. Currently there has been a debate on the introduction of financial derivatives mainly futures at the NSE to leverage on market volatility (risks). Knowledge on dynamics of returns volatility will hasten this innovation as well as pricing of such financial products.

These findings are equally important to the Central Bank particularly on the recent U.S tapering arising from monetary tightening and its possible effects on volatility via foreign investors' re-allocation of portfolios. For example, what would be the policy intervention arising from the exit of foreign investors? Of outmost concern would be how long such occurrences are likely to persist, with consequences on market stabilization.

\section{Methodology}

\section{Theoretical framework}

Volatility cannot be observed hence it must be estimated. Several models have been constructed to represent dynamics of stock return volatility in an attempt to forecast it. These are Autoregressive Conditional Heteroscedasticity (ARCH) models introduced by Engle (1982). One of the shortcomings of the ARCH model in the modelling and analysis of stock returns volatility is that it has only one memory period. Empirical evidence shows that high ARCH order has to be selected in order to capture the dynamic of the conditional variance. The high ARCH order implies that many parameters have to be estimated

We therefore turn to Generalized Autoregressive Conditional Heteroscedasticity (GARCH) model developed by Bollerslev (1986). This model is based on an infinite ARCH specification which allows us to dramatically reduce the number of estimated parameters from an infinite number to just a few. In Bollerslev's GARCH model the conditional variance is a linear function of past squared innovations and previous conditional variances.

\section{Model specification}

Given that stock returns are non-normally distributed, Autoregressive Moving Average (ARIMA) models may not appropriately capture stock volatility. Financial time series data often exhibit some well-known characteristics. First, large changes tend to be followed by large changes and small changes tend to be followed by small changes. Secondly the series 
often exhibit leptokurtosis, where the distribution of the returns is fat-tailed (i.e. relative high probability for extreme values). The GARCH model successfully captures the first property, but sometimes fails to capture the fat-tail property. This has led to the use of non-normal distributions to better model the fat-tailed characteristic. A simple random walk model is thus specified as:

$\mathrm{R}_{\mathrm{t}}=\mu+\alpha_{1} \mathrm{R}_{\mathrm{t}-1}+\varepsilon_{\mathrm{t}}$

Where $R_{t}$ is the daily continuously compounded stock return at time $t$

$\mu$ is the daily mean return

$\varepsilon_{\mathrm{t}}$ is the error term at period $t$.

However, the random walk hypothesis does not hold especially in an inefficient stock market that is characterised by high information asymmetry. Poterba and Summers (1988), Fama and French (1988) and others posit that there is tendency for stock prices to revert back to their mean in the long run thus violating the principle behind the random walk hypothesis and the efficient market hypothesis in general. As a result, the variance of stock returns is not constant hence that need to model for heteroscedasticity.

We therefore specify a symmetric GARCH. The model is based on infinite order ARCH and as a result, the current stock return volatility depends on previous days' volatility. In the symmetric models, the conditional variance only depends on the magnitude, and not the sign, of the stock returns. The model is specified as follows:

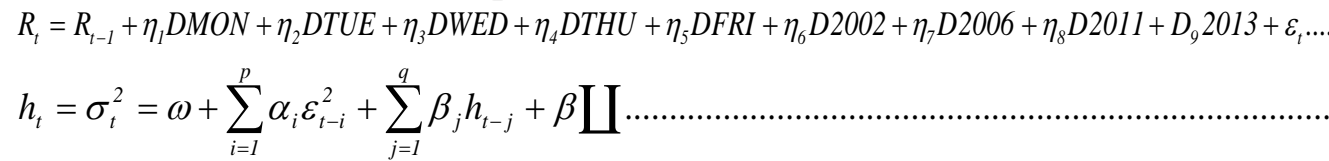

Where:

$R_{t}$ is the daily continuously compounded stock return at time

$\omega$ is the daily mean stock return

$h_{t}=\sigma_{t}^{2}$ is the conditional variance of the daily stock returns

$\alpha$ is the arch effect

$D M O N, D T U E, D W E D, D T H U \& D F R I$ are the day of the week dummies

D2002,D2006,2011\& 2013 are the annual policy and institutional dummies

Џ is the vector capturing seasonal effects.

The day of the week dummies are introduced to capture whether the day of the week anomalies in the stock market exist. On the other hand, the annual policy and institutional dummies are meant to capture the effect of the introduction of a new policy or institutional changes on the daily stock returns. 
Equation (3) and (4) are the mean and the variance equations respectively where:

$p>0, q>0$ while $\omega, \alpha, \beta \geq 0$. If $p=0$ then the GARCH model collapses into the $\mathrm{ARCH}$ model. If $\mathrm{p}=\mathrm{q}=0$ then the error $\varepsilon_{\mathrm{t}}$ is a white process implying that: $\mathrm{E}\left[\varepsilon_{\mathrm{t}}\right]=0, \operatorname{Var}\left[\varepsilon_{\mathrm{t}}\right]=\sigma^{2}$ and

$\mathrm{E}\left[\varepsilon_{\mathrm{t}}, \varepsilon_{\mathrm{s}}\right]=0 \mathrm{\gamma t} \neq \mathrm{s}$. $h_{t}$ is the conditional variance of the daily stock returns signifying the conditional stock returns' volatility. The day of the week anomaly, (seasonal effects) is captured by the Џ vector. If $\sum \alpha+\sum \beta=1$ the shock to the present stock returns volatility is more likely to be persistent for a long time in the future and the process is therefore referred to as the Integrated GARCH (IGARCH). If $\sum \alpha+\sum \beta$ is very close to unity then there exists strong persistence of shock to stock volatility.

We specify GARCH $(1,1)$ model as follows:

$h_{t}=\sigma_{t}^{2}=\omega+\alpha \varepsilon_{t-1}^{2}+\beta_{j} h_{t-1}+\coprod$

We also use the GARCH in mean model to capture the relationship between conditional volatility and the expected stock returns. It is an extension of the GARCH model by Engle et al (1987) in which the conditional mean is expressed as an explicit function of the conditional variance. The GARCH in mean equation is specified as:

$\mathrm{R}_{\mathrm{t}}=\Omega_{t}+\lambda_{1} h_{t}+\lambda_{2} D M O N+\lambda_{3} D T U E+\lambda_{4} D W E D+\lambda_{5} D T H U+\lambda_{6} D F R I+\lambda_{7} D 2002+\lambda_{8} D 2006+\lambda_{9} D 2011+\lambda_{9} D_{10} 2013+\mu_{t} \ldots(6)$

$\varepsilon_{\mathrm{t}} / \Psi_{\mathrm{t}-1} \sim N\left(0, h_{t}\right)$

$\mathrm{h}_{\mathrm{t}}=\sigma_{t}^{2}=\omega+\sum_{i=1}^{p} \alpha_{i} \varepsilon_{t-i}^{2}+\sum_{j=1}^{q} \beta_{j} h_{t-i}+\chi \coprod$

Equation (6) is the mean equation while equation (8) is the variance equation. Equation (7) gives the distribution of condition variance. In the model:

$\Omega_{\mathrm{t}^{-}}$The mean return conditional on past information $\left(\Psi_{\mathrm{t}-1}\right)$

$\mathrm{R}_{\mathrm{t}}-$ stock return

$\lambda_{1}-$ The time varying risk premium

$\alpha_{j}$ - The ARCH effect (volatility clustering)

The model imposes restrictions; $\omega>0 \alpha_{j}, \beta_{j} \geq 0$ to ensure that conditional variance is non- negative. In addition, $\alpha+\beta$ measures the responsiveness of shocks to volatility over time. A sum greater that unity imply that shocks to stock returns are sustained over time while a sum less than unity imply that shocks decline over time.

Therefore, our GARCH - in - mean $(1,1)$ was defined as follows: $h_{t}=\sigma_{t}^{2}=\omega+\alpha_{1} \varepsilon_{t-1}^{2}+\beta_{1} h_{t-1}+\chi \coprod$

We also estimate asymmetric GARCH models to determine the validity of the symmetric distribution of null hypothesis. Though the GARCH models can successfully capture the thick tail returns, and the 
volatility clustering, they are poor models if one wishes to capture the leverage effect since the conditional variance is a function only of the magnitudes of the past values and not their sign.

The conditional variance $\sigma_{t}^{2}$ of the daily stock returns given information at time $t$,is non-negative with probability one. In GARCH models this property is assured by making $\sigma_{t}^{2}$ a linear combination of positive random variables. Another way of making $\sigma^{2}$ non-negative is by making $\ln \left(\sigma_{t}^{2}\right)$ linear in some function of time. This formulation leads to the asymmetric GARCH model, Exponential GARCH, proposed by Nelson (1991). The general representation of $\operatorname{EGARCH}(p, q)$ model is specified as follows:

$\operatorname{Ln}\left(\mathrm{h}_{\mathrm{t}}\right)=\operatorname{Ln} \sigma_{\mathrm{t}}^{2}=\omega+\sum_{j=1}^{p} \beta_{j} \operatorname{Ln}\left(\sigma_{t-j}^{2}\right)+\sum_{i=1}^{q} \alpha_{i}\left\{\left|\frac{\varepsilon_{t-i}}{\sigma_{t-i}}\right|-\sqrt{\frac{2}{\pi}}\right\}-\gamma_{i} \frac{\varepsilon_{t-i}}{\sigma_{t-i}}$

Where: $\frac{\varepsilon_{t-i}}{\sigma_{t-i}}$ is the standardized error term and $\lambda$ is the asymmetric parameter.

From the general representation, we specified EGARCH $(1,1)$ as follows

$\operatorname{Ln}\left(\mathrm{h}_{\mathrm{t}}\right)=\operatorname{Ln} \sigma_{\mathrm{t}}^{2}=\omega+\beta_{j} \operatorname{Ln}\left(\sigma_{t-1}^{2}\right)+\alpha_{1}\left\{\left|\frac{\varepsilon_{t-1}}{\sigma_{t-1}}\right|-\sqrt{\frac{2}{\pi}}\right\}-\gamma \frac{\varepsilon_{t-1}}{\sigma_{t-1}}$

$h_{t}=\sigma_{t}^{2}$ is the conditional stock variance while $\omega, \beta, \lambda$ are constant parameters. The term in parenthesis represents the magnitude effect. The main advantage of this model compared to the GARCH model is that it is capable of taking into account the asymmetric effect of volatility on stock returns which is measured by parameter $\gamma$. Since the model is in logarithms then this allows both the good and bad news to affect stock return volatility in similar manner thus the estimated conditional variance is always positive. The model also rules out the imposition of the non-negativity condition on the estimated model parameters as opposed to the GARCH model.

We also used the threshold GARCH which is ideal for capturing information asymmetry in financial data. This model was proposed by Zakoian (1994) and shows that bad news has a greater impact on stock return volatility than good news. It is mainly used to test whether a decline on stock return is followed by higher volatility compared to upward movements of the same scale. The general specification for conditional variance equation under $\operatorname{TGARCH}(p, q)$ model is given as:

$\mathrm{h}_{\mathrm{t}}=\sigma_{t}^{2}=\omega+\sum_{i=1}^{q}\left(\alpha_{i}+\gamma_{i} d_{t-i}\right) \varepsilon_{t-1}^{2}+\sum_{j=1}^{p} \beta_{j} \sigma_{t-j}^{2}$ 

follows:

The conditional variance equation TGARCH $(1,1)$ is specified as

$h_{t}=\sigma_{t}^{2}=\omega+\alpha_{1} \varepsilon_{t-1}^{2}+\gamma d_{t-1} \varepsilon_{t-1}^{2}+\beta_{1} \sigma_{t-1}^{2}$

Where $d_{t-1}$ is a dummy where

$$
d_{t-1}=\left\{\begin{array}{lll}
o \text { if } & \varepsilon_{t-1}<O, \text { bad news } \\
1 \text { if } & \varepsilon_{t-1} \geq 0, \text { good news }
\end{array},\right.
$$

And $\gamma$ is the asymmetry or leverage term of the model. If we set $\gamma_{i}$ $=0$, the model collapses to the standard GARCH forms. Otherwise, when the shock is positive (such as good news) the effect on volatility is given by $\alpha_{i}$ However in case of a negative shock (such as bad news) the effect on volatility is given by $\alpha_{i}+\gamma_{i}$. Therefore, if $\gamma_{i}$ is positive and significant, this would imply that negative shocks have a larger effect on conditional stock returns volatility than the positive shock of the same magnitude hence we conclude there is evidence of leverage effect in stock returns.

\section{Definition and measurement of variables}

From our empirical models, stock returns refer to the continually compounded daily rate of returns on stocks. They are defined by the first difference of the logarithm of daily stock indices, computed as $\mathrm{R}_{\mathrm{t}}=\mathrm{Log}$ $\left(\mathrm{P}_{t} / \mathrm{P}_{\mathrm{t}-1}\right)$ where $\mathrm{P}_{\mathrm{t}}$ represents the value of the NSE-20 share index at time $t$. In this study the NSE-20 share indices is used as a proxy for the entire market price since it is deemed to be the most appropriate yardstick for measuring the equity market performance. The index constitutes the "blue chip" companies that are viewed as representatives of the entire NSE performance and form the bulk of the entire market capitalization, market turnover and trade volume. Using the recently introduced All- share index and the FTSE index risks the problem of fewer data points that may not capture long memory volatility at NSE appropriately.

DMON through DFRI are the dummy variables that capture the day of the week (anomaly) effect.D2002 captures the new regulations on foreign investors where a $25 \%$ minimum reserve of the issued share capital (during an IPO and Government of Kenya privatization) was for locals while the $75 \%$ was a free float for all classes of investors. D2006 captures the introduction of live trading upon the introduction of ATS as well as cross listing in Uganda and Tanzania stock exchange. D2011 captures the change in equity settlement cycle from $\mathrm{T}+4$ to $\mathrm{T}+3$. D2013 captures the onset of U.S tapering on the fourth quarter of 2013. December 2013 onwards to December 2014 represents the period under tapering. 


\section{Econometric Approach}

Stationarity and autocorrelation tests was conducted before applying any ARCH type model to determine the order of integration for stock returns. We estimated GARCH $(1,1)$ model and tested for normality and serial correlation of the error term, and ARCH effect to determine normality, clustering volatility and long memory in stock returns.

To predict the volatility for the time series, we fitted the GARCHmodel to the time series in question, via the estimation of the parameters in the model. The most common method of this estimation is the maximumlikelihood estimation (MLE).When dealing with GARCH models the assumption of stationarity of the stock returns is basic for the statistical analysis. This implies constraints on the estimated parameters in the maximum likelihood-estimation.

To analyse the investors' risk premia at the market with reference to time changes, we fitted the GARCH-in-mean $(1,1)$ model. However to fit the leverage effect and idiosyncratic risk and their effect on returns volatility we estimated the EGARCH $(1,1)$ and TGARCH $(1,1)$ models and compared the two on their efficiency to capture information asymmetry at NSE.

\section{Sources of Data}

This study used daily closing prices covering the period $2^{\text {nd }}$ January 2001 to $31^{\text {st }}$ December 2014.The data was sourced from Nairobi Securities Exchange.

\section{Empirical findings}

Table 1 shows mean daily returns ranging from -0.0006 to 0.0005 which implies that with the introduction of the new regulation there is increased participation by local investors which reflects increased confidence in the market. This marginally increases upon cross listing and live trading. The reduction in equity settlement cycle from $\mathrm{T}+4$ to $\mathrm{T}+3$ further surged the daily mean returns upwards. However, the news on monetary tightening policy in US affected the mean daily returns negatively. The mean returns were however positive compared to the pre 2002 period. The daily returns for the entire sample averaged at 0.0001 .

Table 1: Summary Statistics for Stock Returns

\begin{tabular}{|c|c|c|c|c|c|c|}
\hline & $\begin{array}{c}2^{\text {nd }} \text { Jan } 2001 \\
\text { to } 31^{\text {st }} \text { Dec } \\
2001 \\
\end{array}$ & $\begin{array}{c}2^{\text {nd }} \text { Jan } 2002 \\
\text { to } 31^{\text {st }} \text { Dec } \\
2005 \\
\end{array}$ & $\begin{array}{c}2^{\text {nd }}{ }^{\text {Jan }} 2006 \\
-31^{\text {st }} \text { Dec } \\
2010 \\
\end{array}$ & $\begin{array}{c}\text { 2nd Jan } \\
2011 \text { to } 31^{\text {st }} \\
\text { Dec } 2012 \\
\end{array}$ & $\begin{array}{c}\text { 2nd Jan } 2013 \text { to } \\
31^{\text {Jt }} \text { December } \\
2014\end{array}$ & $\begin{array}{c}\text { Entir } \\
\text { e } \\
\text { sampl } \\
\text { e } \\
\end{array}$ \\
\hline Mean & -0.0006 & 0.0005 & 0.0000 & 0.0001 & 0.0003 & $\begin{array}{c}0.000 \\
1\end{array}$ \\
\hline $\begin{array}{l}\text { Medi } \\
\text { an }\end{array}$ & -0.0004 & 0.0002 & 0.0000 & 0 & 0.0003 & $\begin{array}{c}0.000 \\
1\end{array}$ \\
\hline $\begin{array}{l}\text { Maxi } \\
\text { mum }\end{array}$ & 0.0085 & 0.0202 & 0.1287 & 0.0913 & 0.0168 & 0.128 \\
\hline
\end{tabular}




\begin{tabular}{|c|c|c|c|c|c|c|}
\hline & & & & & & 7 \\
\hline $\begin{array}{l}\text { Mini } \\
\text { mum }\end{array}$ & -0.0104 & -0.0178 & -0.1298 & -0.0913 & -0.0071 & $\begin{array}{c}- \\
0.129 \\
8 \\
\end{array}$ \\
\hline $\begin{array}{c}\text { Std. } \\
\text { Dev. }\end{array}$ & 0.0025 & 0.0037 & 0.0077 & 0.0067 & 0.0028 & $\begin{array}{l}0.00 \\
59\end{array}$ \\
\hline $\begin{array}{l}\text { Skew } \\
\text { ness }\end{array}$ & -0.1904 & 0.4097 & -0.0035 & -0.0082 & 1.4258 & $\begin{array}{l}0.00 \\
98 \\
\end{array}$ \\
\hline $\begin{array}{c}\text { Kurto } \\
\text { sis }\end{array}$ & 6.2037 & 8.2458 & 136.9710 & 142.4804 & 9.8412 & $\begin{array}{c}188.0 \\
897\end{array}$ \\
\hline $\begin{array}{c}\text { Jarqu } \\
\text { e- } \\
\text { Bera }\end{array}$ & 108.4251 & 1164.009 & 935551.0 & 411792.8 & 636.3176 & $\begin{array}{l}4679 \\
100\end{array}$ \\
\hline $\begin{array}{l}\text { Proba } \\
\text { bility }\end{array}$ & 0.0000 & 0.0000 & 0.0000 & 0.0000 & 0.0000 & $\begin{array}{l}0.00 \\
00\end{array}$ \\
\hline Sum & -0.1498 & 0.4646 & 0.0501 & -0.0304 & 0.0812 & $\begin{array}{l}0.41 \\
57 \\
\end{array}$ \\
\hline $\begin{array}{l}\text { Sum } \\
\text { Sq. } \\
\text { Dev. }\end{array}$ & 0.0012 & 0.0135 & 0.0735 & 0.0225 & 0.0022 & $\begin{array}{c}0.113 \\
2\end{array}$ \\
\hline $\begin{array}{c}\text { Obse } \\
\text { rvatio } \\
\text { ns }\end{array}$ & 250 & 991 & 1251 & 508 & 469 & $\begin{array}{l}346 \\
8\end{array}$ \\
\hline
\end{tabular}

Note: Table 1 is divided into six different parts. The pre 2002 capture the period before the Introduction of the new regulations on foreign investors, after 2002 but before 2006 captures the introduction of the new regulation, after 2006 but before 2011 captures cross listing and the introduction of live trading, after 2011 but before 2013 captures the change in equity settlement cycle from $\mathrm{T}+4$ to $\mathrm{T}+3$, after 2012 captures the effects of US tapering

With regard to skewness of returns, the pre 2002, onset of cross listing, live trading and change in equity settlement cycle shows negative skews (extreme left tails) while the new regulation of 2002 and the US tapering effect posting positive skews (extreme right tails). This finding imply spill over volatilities from other markets as a result of cross listing which leads into negatively skewed returns. On the other hand, new regulation of 2002 increased participation by local investors thereby increasing market confidence hence the positively skewed returns.

The entire period shows that daily returns exhibited fat tails (leptokurtosis) as evidenced by kurtosis greater than 3 particularly with the introduction of live trading and cross listing in Uganda and Tanzania. This is perhaps due to the spill over volatilities from the Ugandan and the Tanzanian market into the NSE. Introduction of live trading increases the number of trading volumes which is likely to increases volatility through increased speculation.

Introduction of live trading and cross listing shows the highest volatility of 0.0077 . This supports the evidence of spill over volatilities from 
cross listing and increased trading volumes from live trading. Similarly, the new regulation of 2002 increased volatility of daily stock returns from 0.0022 to 0.0037 . However, the change in equity settlement cycle lowers volatility from 0.0077 to 0.0067 . The Jarque-Bera values negates the null hypothesis of normal distribution.

Summary Statistics for Weekdays

Table 2: Summary statistics for the days of the week

\begin{tabular}{|c|c|c|c|c|c|}
\hline & MON & TUE & WED & THUR & FRI \\
\hline Mean & 0.0001 & -0.0008 & 0.0004 & -0.0006 & 0.0001 \\
\hline Median & 0.0002 & 0.0001 & 0.0001 & 0.0001 & 0.0001 \\
\hline Maximum & 0.0913 & 0.0349 & 0.1287 & 0.0302 & 0.0469 \\
\hline Minimum & -0.0349 & -0.1298 & -0.0154 & -0.0469 & -0.05 \\
\hline Std. Dev. & 0.0059 & 0.0076 & 0.0063 & 0.0043 & 0.0046 \\
\hline Skewness & 6.2505 & -9.9672 & 13.0612 & -1.4848 & -0.0427 \\
\hline Kurtosis & 101.9303 & 160.8043 & 259.6591 & 30.2609 & 40.6776 \\
\hline Jarque-Bera & 271373.9 & 691521.9 & 1819205.0 & 20554.02 & 38743.53 \\
\hline Probability & 0.0000 & 0.0000 & 0.0000 & 0.0000 & 0.0000 \\
\hline Sum & 0.0832 & -0.0533 & 0.2942 & 0.0404 & 0.0512 \\
\hline Sum Sq. Dev. & 0.0225 & 0.0383 & 0.0263 & 0.0121 & 0.0140 \\
\hline Observations & 693 & 694 & 694 & 694 & 693 \\
\hline
\end{tabular}

Table 2 shows day specific summary statistics. Wednesday has the highest positive daily mean returns of 0.0004 with fattest tails followed by Monday and Friday at 0.0001 and 0.00008 respectively. However, Tuesday and Thursday have negative daily mean returns with Tuesday having the largest negative returns. This perhaps explains the effects of announcements for auctions in government's treasury bills on Thursdays and the actual trading taking place on Tuesdays. Tuesday has higher volatility in stock return relative to other days. Therefore, Tuesdays present a case of leverage effect; - a negative relationship between volatility and stock returns since it experiences the highest negative daily returns as well as highest volatility. On the contrary Thursdays have the lowest volatility.

Figure 1 shows volatility clustering of return series of the NSE 20share index for the period $2^{\text {nd }}$ January 2001 to $31^{\text {st }}$ December 2014. The figure shows evidence of volatility clustering. Period of low volatility tends to be followed by period of low volatility for a prolonged period and the period of high volatility is followed by period of high volatility for a prolonged period, which means the volatility is clustering and the return series vary around the constant mean but the variance is changing with time. 
Figure 1: Volatility clustering of stock returns for period 2nd January 2001 to 31 December 2014

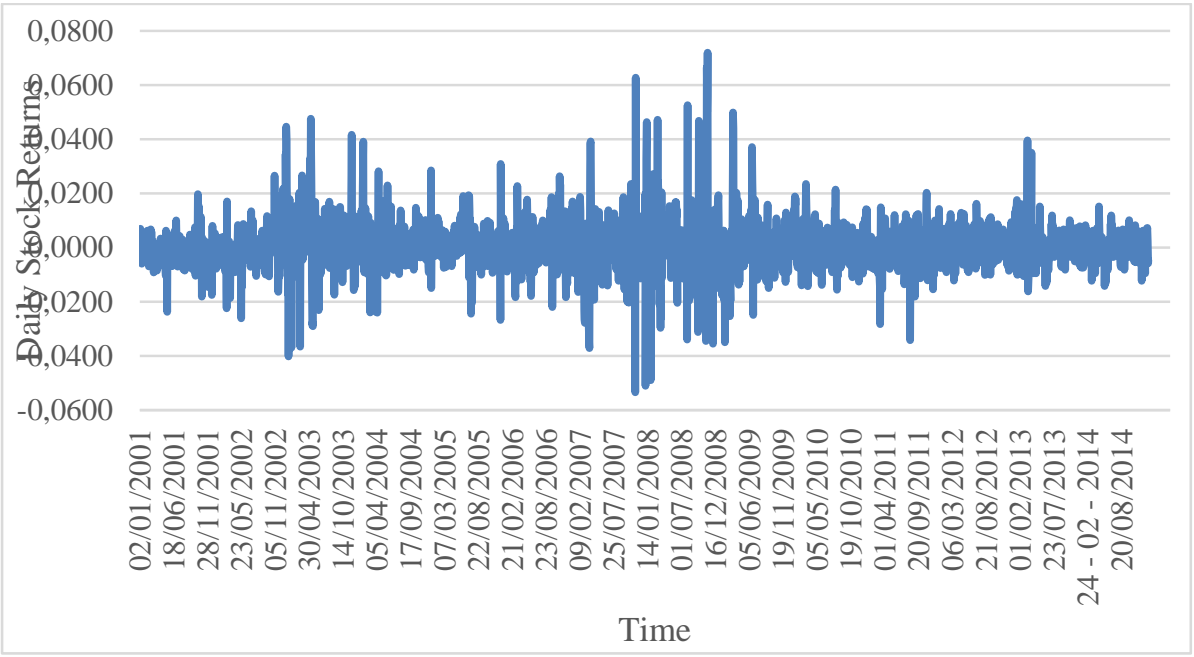

\section{Test for stationarity}

Table 3 shows stationarity test based on the Box and Jenkins (1976). The use of the dickey fuller test for unit root reveals that the daily stock returns are integrated of order zero implying the absence of unit root. Table 3 also shows the presence of heteroscedasticity tested using ARCH-LM test. The ADF test statistics reported in Table 3 reject the hypothesis at $1 \%$ level with the critical value of -3.43 of a unit root in the return series. Thus, the results confirm that the series are stationary. We applied the ARCH-LM test to find out the presence of ARCH effect in the residuals of the return series. Since $\mathrm{p}<0.05$, we reject the null hypothesis of 'no ARCH effect' at $1 \%$ level. This confirms the presence of ARCH effects in the residuals which leads us to the estimation of GARCH models. We therefore proceeded with determining the best fitted GARCH model to the return series.

Table 3: Unit Root Test (ADF)

\begin{tabular}{|c|c|c|c|c|}
\hline & \multicolumn{2}{|c|}{ With Intercept } & \multicolumn{2}{c|}{ With Intercept and Trend } \\
\hline $\begin{array}{c}\text { ADF test } \\
\text { statistics }\end{array}$ & $\begin{array}{c}\text { Calculated } \\
\text { Values }\end{array}$ & Critical Values & $\begin{array}{c}\text { Calculated } \\
\text { Values }\end{array}$ & Critical Values \\
\hline $\mathrm{R}_{\mathrm{t}}$ & -29.936 & -3.432 (at 1\%) & -29.931 & -3.961 (at 1\%) \\
\hline AR 1 & -29.932 & -2.862 (at 5\%) & & -3.411 (at 5\%) \\
\hline & & -2.432 (at 1\%) & -29.928 & -3.961 (at 1\%) \\
\hline $\begin{array}{c}\text { ARCH-LM test } 5 \%) \\
\text { Prob. (1) }\end{array}$ & & & $-3.411($ at 5\%) \\
\hline
\end{tabular}

\section{Results and Discussion}

The results for GARCH $(1,1)$ model are shown in table 4, which reveals the parameter of GARCH is statistically significant. The ARCH and 
GARCH terms are highly significant at $1 \%$ level. In the conditional variance equation, the estimated ARCH coefficient is considerably greater than GARCH coefficient which implies that the market has a short memory and that volatility is more sensitive to new surprises in the market values than its lagged values. It shows that the volatility is persistent. The magnitude of the ARCH and GARCH parameters determine the volatility persistence in time series. The sum of these coefficients is 0.49 , which is less than unity indicating that the shock will not persist for many future periods. All trading days have negative returns with the exception of Friday in model 1 to 4 . However, for the entire sample negative daily returns are reported for all week days. D2002 and D2013 post significantly positive daily returns implying that introduction of the new regulations on foreign investors and U.S tapering positively influences daily stock returns at the NSE.

\begin{tabular}{|c|c|c|c|c|c|}
\hline \multicolumn{6}{|c|}{ Table 4: GARCH $(1,1)$ Results } \\
\hline \multicolumn{6}{|c|}{ Mean equation } \\
\hline & 1 & 2 & 3 & 4 & 5 \\
\hline Constant & $0.0000(0.7568)$ & & & & \\
\hline Return (t-1) & $0.4253(0.000)$ & $0.5504(0.0000)$ & $0.4881(0.0000)$ & $0.4719(0.0000)$ & $0.4022(0.0000)$ \\
\hline DMON & & $-0.0003(0.1201)$ & $-0.0002(0.4548)$ & $-0.0005(0.1374)$ & $-0.0078(0.0082)$ \\
\hline DTUE & & $-0.0015(0.0000)$ & $-0.0004(0.0241)$ & $-0.0019(0.0000)$ & $-0.0008(0.0000)$ \\
\hline DWED & & $-0.0006(0.7285)$ & $0.00034(0.1507)$ & $-0.0032(0.3478)$ & $-0.0006(0.1086)$ \\
\hline DTHUR & & $-0.0003(0.0051)$ & $-0.0002(0.0703)$ & $-0.0009(0.0041)$ & $-0.0006(0.0264)$ \\
\hline DFRI & & $0.0032(0.0000)$ & $0.0001(0.5810)$ & $0.0021(0.0000)$ & $-0.0005(0.0499)$ \\
\hline D2002 & & & & $0.0004(0.2247)$ & $0.0009(0.0001)$ \\
\hline D2006 & & & & $0.0012(0.0000)$ & $-0.0004(0.2814)$ \\
\hline D2011 & & & & $-0.00281(0.0000)$ & $-0.0001(0.8058)$ \\
\hline D2013 & & & & $0.0017(0.0000)$ & $0.0004(0.2361)$ \\
\hline \multicolumn{6}{|c|}{ Conditional Volatility Equation } \\
\hline Constant & $0.0002(0.0000)$ & $0.0000(0.0000)$ & $0.00053(0.0000)$ & $0.0001(0.0000)$ & $0.0000(0.0000)$ \\
\hline ARCH (1) & $0.1334(0.0000)$ & $1.8511(0.0000)$ & $0.5696(0.0000)$ & $1.8662(0.0000)$ & $0.3312(0.0000)$ \\
\hline GARCH (1) & $-0.0099(0.6816)$ & $0.0318(0.0000)$ & $0.1458(0.0000)$ & $0.0534(0.0000)$ & $0.1608(0.0000)$ \\
\hline DMON & & & $0.0005(0.0000)$ & & $0.0000(0.0000)$ \\
\hline DTUE & & & $-0.0001(0.0000)$ & & $0.0000(0.0090)$ \\
\hline DWED & & & $0.0001(0.0000)$ & & $0.0001(0.0000)$ \\
\hline DTHUR & & & $-0.0001(0.0000)$ & & $-0.0001(0.0000)$ \\
\hline D2002 & & & & & $0.0001(0.0000)$ \\
\hline D2006 & & & & & $0.0001(0.0000)$ \\
\hline D2011 & & & & & $0.0002(0.0000)$ \\
\hline D2013 & & & & & $-0.0002(0.0059)$ \\
\hline R2 & -0.2777 & -0.4653 & -0.3516 & -0.377 & -0.2529 \\
\hline Adjusted R2 & -0.2794 & $\begin{array}{l}-0.4691 \\
\end{array}$ & $\begin{array}{l}-0.3566 \\
\end{array}$ & -0.3821 & -0.2606 \\
\hline Log likelihood & 12967.79 & 13058.15 & 13332.11 & 13155 & 13411.16 \\
\hline Durbin - Watson & 2.9516 & 3.0492 & 3.0149 & 2.9679 & 2.9276 \\
\hline \multicolumn{6}{|c|}{ ARCH - LM TEST } \\
\hline Constant & $0.993(0.0015)$ & $0.999(0.0000)$ & $0.991(0.0000)$ & $1.0107(0.0000)$ & $0.9835(0.0000)$ \\
\hline Residual squared & $0.0088(0.6137)$ & $0.0002(0.9885)$ & $0.0087(0.6195)$ & $0.0001(0.9937)$ & $0.0126(0.4685)$ \\
\hline Observed R2 & $0.1549(0.6135)$ & $0.0002(0.9885)$ & $0.2467(0.6195)$ & $0.0006(0.9937)$ & $0.5260(0.4683)$ \\
\hline F - Statistics & $0.2549(0.6137)$ & $0.0002(0.9885)$ & $0.2466(0.6195)$ & $0.0006(0.9937)$ & $0.5258(0.4685)$ \\
\hline
\end{tabular}


The GARCH-M model (See Table 5) captures the effect of volatility on the daily stock returns thus revealing the risk premium in the market. The model is estimated by allowing the mean equation of the return series to depend on a function of the conditional variance. The coefficient of conditional variance (GARCH) in the mean equation value is positive and statistically significant. This implies that there is a significant impact of volatility on the expected return, indicating risk-return trade off over time. Presence of risk premium confirms Pagan and William (1990) who asserts that investments in financial assets are a function of risk premium which is predictable.

\begin{tabular}{|c|c|c|c|c|c|}
\hline \multicolumn{6}{|c|}{ Table 5: GARCH - M $(1,1)$ Results } \\
\hline \multicolumn{6}{|c|}{ Mean equation } \\
\hline & 1 & 2 & 3 & 4 & 5 \\
\hline Constant & $-0.0014(0.0000)$ & & & & \\
\hline Return (t-1) & $0.4197(0.0000)$ & $0.4809(0.0000)$ & $-0.1160(0.0015)$ & $0.4732(0.0000)$ & $-0.1185(0.0043)$ \\
\hline DMON & & $-0.0118(0.0268)$ & $-0.0061(0.0060)$ & $0.0002(0.5661)$ & $-0.0055(0.1019)$ \\
\hline DTUE & & $-0.0028(0.0000)$ & $-0.0031(0.0345)$ & $-0.0010(0.0034)$ & $-0.0061(0.0547)$ \\
\hline DWED & & $-0.0018(0.0126)$ & $-0.0048(0.0081)$ & $0.0007(0.0502)$ & $-0.0054(0.0832)$ \\
\hline DTHUR & & $-0.0016(0.300)$ & $-0.0029(0.0029)$ & $-0.0001(0.7415)$ & $-0.0045(0.1333)$ \\
\hline DFRI & & $0.0009(0.1237)$ & $-0.0048(0.0087)$ & $0.0029(0.0000)$ & $-0.0063(0.0522)$ \\
\hline D2002 & & & & $0.005(0.1626)$ & $0.0019(0.4134)$ \\
\hline D2006 & & & & $0.0013(0.0000)$ & $-0.028(0.0045)$ \\
\hline D2011 & & & & $-0.0028(0.0000)$ & $0.0007(0.1901)$ \\
\hline D2013 & & & & $0.0015(0.0000)$ & $0.0025(0.1864)$ \\
\hline GARCH & $0.2828(0.0000)$ & $0.2278(0.0051)$ & $0.4834(0.0024)$ & $-0.1849(0.0000)$ & $0.4906(0.0175)$ \\
\hline \multicolumn{6}{|c|}{ Conditional Volatility Equation } \\
\hline Constant & $0.0002(0.0000)$ & $0.0000(0.0000)$ & $0.0000(0.0000)$ & $0.0000(0.0000)$ & $0.0003(0.0000)$ \\
\hline ARCH (1) & $0.2694(0.0000)$ & $0.5269(0.0000)$ & $0.1496(0.0000)$ & $1.8289(0.0000)$ & $0.1482(0.0000)$ \\
\hline GARCH (1) & $-0.0241(0.0214)$ & $-0.0195(0.1595)$ & $0.5972(0.0000)$ & $0.0670(0.0000)$ & $0.5942(0.0000)$ \\
\hline DMON & & & $0.0001(0.0000)$ & & $-0.0001(0.0594)$ \\
\hline DTUE & & & $-0.0001(0.0000)$ & & $-0.0001(0.0000)$ \\
\hline DWED & & & $0.0000(0.0001)$ & & $-0.0002(0.0140)$ \\
\hline DTHUR & & & $-0.0001(0.0000)$ & & $-0.0002(0.0000)$ \\
\hline D2002 & & & & & $-0.0002(0.6275)$ \\
\hline D2006 & & & & & $0.0003(0.2129)$ \\
\hline D2011 & & & & & $0.0002(0.3602)$ \\
\hline D2013 & & & & & $-0.0003(0.0000)$ \\
\hline R2 & -0.2505 & -0.3465 & 0.0291 & -0.4866 & 0.0215 \\
\hline Adjusted R2 & $\begin{array}{l}-0.2524 \\
\end{array}$ & -0.3503 & 0.0253 & -0.4925 & 0.0151 \\
\hline Log likelihood & 12946.98 & 12891.68 & 12591.38 & 13171.04 & 12334.65 \\
\hline Durbin - Watson & 2.9448 & 2.9754 & 1.904 & 2.754 & 1.9236 \\
\hline \multicolumn{6}{|c|}{ ARCH - LM TEST } \\
\hline Constant & $0.8393(0.0011)$ & $0.7235(0.0005)$ & $0.4890(0.0000)$ & $1.0083(0.0000)$ & $0.4153(0.0000)$ \\
\hline Residual squared & $0.0120(0.4913)$ & $0.0078(0.6573)$ & $0.0264(0.1313)$ & $0.0011(0.9484)$ & $0.0275(0.152)$ \\
\hline Observed R2 & $0.4739(0.0492)$ & $0.1970(0.6571)$ & $2.2783(0.1312)$ & $0.0042(0.9484)$ & $2.4825(0.1151)$ \\
\hline F - Statistics & $0.4737(0.4714)$ & $0.1969(0.6573)$ & $2.2785(0.1313)$ & $0.0042(0.9484)$ & $2.4829(0.1152)$ \\
\hline
\end{tabular}

Analysis of the conditional variance equation reveals highly significant ARCH and GARCH parameters at 1\% level. The sum of the two parameters of interest shows that volatility shocks on daily returns at the 
NSE are transitory. However, exclusion of week days and policies and regulations from the mean variance equation sums up to 1.88 as presented in model 3. Therefore in the absence of regulations and policies, volatility shocks would persist for long. Tuesday and Thursday indicate a higher market volatility with Thursday being the most pronounced which is consistent with the summary statistics reported in Table 2. This can perhaps be traced to the Treasury bills trading where the auctions announcements are done on Thursdays with the sale being on Tuesdays. Therefore upon the announcement equity holders' rush to offload their holdings in anticipation of purchasing treasury bills. The day of the week anomaly finding is consistent with the Jaffe and Westerfield (1985) on Australia and Japan markets. However, the ARCH-LM test on the residuals does not exhibit additional ARCH effect for the entire study period. Therefore the variance equation is well specified.

In order to capture the asymmetries in the return series, two models have been used. The Exponential GARCH-M captures the asymmetry at the NSE which is measured by coefficient $\gamma_{i}$ and the result is presented in Table 6. The estimated results indicate that ARCH and GARCH are statistically significant at $1 \%$ level and greater than one. This implies that conditional variance is explosive. Since $\beta<1$ the GARCH model is not an Integrated GARCH (IGARCH) which is consistent with Koutmos (1993) implying that investors at the NSE perceive market booms as not being supported by economic fundamentals and market returns portray speculative bubbles behaviour. The leverage coefficient $\gamma_{i}$, is positive for the entire sample and statistically significant at $5 \%$ level. This indicates that there is no leverage effect in return during the study period. Hence, EGARCH-M $(1,1)$ model does not support the presence of leverage effect on the NSE-20 share return series. The ARCH-LM test statistics reveals that the null hypothesis of no heteroscedasticity in the residuals is accepted.

\begin{tabular}{|c|c|c|c|c|c|}
\hline \multicolumn{7}{|c|}{ Table 6: EGARCH $(1,1)$ Results } \\
\hline \multicolumn{7}{|c|}{ Mean equation } \\
\hline & 1 & 2 & 3 & 4 & 5 \\
\hline Constant & $0.0002(0.5745)$ & & & & \\
\hline Return (t-1) & $0.4358(0.0000)$ & $0.5366(0.0000)$ & $0.4966(0.0000)$ & $0.4198(0.0000)$ & $0.4916(0.0000)$ \\
\hline DMON & & $0.0023(0.0000)$ & $0.0029(0.0000)$ & $0.0014(0.0116)$ & $-0.0009(0.0641)$ \\
\hline DTUE & & $0.0014(0.0000)$ & $0.0016(0.0000)$ & $0.0003(0.6354)$ & $-0.0009(0.0008)$ \\
\hline DWED & & $0.0026(0.0000)$ & $0.0028(0.0000)$ & $0.0018(0.0020)$ & $-0.0005(0.2375)$ \\
\hline DTHUR & & $0.0025(0.0000)$ & $0.0018(0.0000)$ & $0.0012(0.0378)$ & $-0.0067(0.0283)$ \\
\hline DFRI & & $0.0047(0.0000)$ & $0.0039(0.0000)$ & $0.0034(0.0000)$ & $-0.0001(0.9288)$ \\
\hline D2002 & & & & $0.0006(0.1974)$ & $0.0007(0.0006)$ \\
\hline D2006 & & & & $0.0007(0.0014)$ & $0.0001(0.9458)$ \\
\hline D2011 & & & & $-0.0025(0.0000)$ & $-0.0011(0.0006)$ \\
\hline D2013 & $-0.0348(0.6939)$ & $-0.4367(0.0000)$ & $-0.4883(0.0000)$ & $-0.3941(0.0000)$ & $0.0388(0.6094)$ \\
\hline GARCH & \multicolumn{5}{|c|}{ Conditional Volatility Equation } \\
\hline \multicolumn{7}{|c|}{}
\end{tabular}




\begin{tabular}{|c|c|c|c|c|c|}
\hline Constant & $-7.9646(0.0000)$ & $-7.9627(0.0000)$ & $-6.1987(0.0000)$ & $-8.6310(0.0000)$ & $-7.6218(0.0000)$ \\
\hline $\mathrm{ARCH}(\alpha)$ & $0.4377(0.0000)$ & $0.9864(0.0000)$ & $1.0150(0.0000)$ & $0.8960(0.0000)$ & $0.6382(0.0000)$ \\
\hline Asymmetry $(\gamma)$ & $-0.0518(0.0026)$ & $0.0610(0.0094)$ & $-1.1500(0.0000)$ & $-0.0292(0.0966)$ & $0.0220(0.0330)$ \\
\hline GARCH $(\beta)$ & $0.3167(0.0000)$ & & $0.5080(0.0000)$ & $0.2598(0.0000)$ & $0.4240(0.0000)$ \\
\hline DMON & & & $1.3294(0.0000)$ & & $1.2907(0.0000)$ \\
\hline DTUE & & & $-0.8207(0.0000)$ & & $-0.8517(0.0000)$ \\
\hline DWED & & & $1.0452(0.0000)$ & & $0.9851(0.0000)$ \\
\hline DTHUR & & & $-0.4148(0.0000)$ & & $-0.3307(0.0000)$ \\
\hline D2002 & & & & & $0.6472(0.0000)$ \\
\hline D2006 & & & & & $0.9614(0.0000)$ \\
\hline D2011 & & & & & $-0.3679(0.0000)$ \\
\hline D2013 & & & & & $-1.1559(0.0000)$ \\
\hline R2 & -1.6616 & & -384291.8 & -2597859.89 & -0.2356 \\
\hline Adjusted R2 & -1.6632 & & -384996.96 & -2605814.15 & -0.2394 \\
\hline Log likelihood & 12947.67 & 13067.25 & 13321.53 & 13119.77 & 13492.74 \\
\hline Durbin - Watson & 2.7719 & 2.0002 & 1.9937 & 2.005 & 2.9796 \\
\hline \multicolumn{6}{|c|}{ ARCH - LM TEST } \\
\hline Constant & $0.9952(0.0018)$ & $1.0219(0.0002)$ & $1.0327(0.0000)$ & $1.0899(0.0001)$ & $1.0031(0.0000)$ \\
\hline Residual squared & $-0.0003(0.9848)$ & $-0.0012(0.9439)$ & $-0.0031(0.8578)$ & $-0.0013(0.9398)$ & $-0.0019(0.9137)$ \\
\hline Observed R2 & $0.0004(0.9848)$ & $0.0049(0.9439)$ & $0.0321(0.8578)$ & $0.0057(0.9398)$ & $0.0117(0.9137)$ \\
\hline F - Statistics & $0.0004(0.9848)$ & $0.0049(0.9438)$ & $0.0321(0.8578)$ & $0.0058(0.9398)$ & $0.0117(0.9137)$ \\
\hline
\end{tabular}

We also estimated an alternative model Thresh-hold GARCH $(1,1)$ to test for asymmetric volatility in the NSE return and report the results in Table 7. The TGARCH captures the leverage effect at the NSE with $\alpha_{i}$ and $\gamma_{i}$ measuring the impact of bad and good news on the daily stock returns respectively. The sum $\alpha_{i}+\gamma_{i}$ gives the impact of bad news or the leverage effect, while $\beta$ measures the degree of persistence in conditional variance. $\gamma_{i}$ $=-0.0303$ for the entire sample and insignificant. Consistent with the EGARCH model, this indicates that there is no leverage effect in return during the study period. This implies that negative shocks or bad news do not have a greater effect on the conditional variance than the positive shocks or good news. Therefore, the introduction of policies and regulations minimizes market information symmetry at NSE. The ARCH-LM test statistic does not show any additional ARCH effects in the residuals, which implies that the variance equation is well specified.

The best fitted models both in symmetric as well as in asymmetric effect are selected based on the highest log likelihood value. The log likelihood value $(13411.16)$ is high for GARCH $(1,1)$ compared to GARCHM $(1,1)$. Hence GARCH $(1,1)$ model is found to be the best fitted model. The $\log$ likelihood value $(13492.74)$ for $\operatorname{EGARCH}(1,1)$ is higher relative to that of the TGARCH hence the model seems to be an adequate description of asymmetric volatility process. 
Table 7: T-GARCH $(1,1)$ Results

\begin{tabular}{|c|c|c|c|c|c|}
\hline \multicolumn{6}{|c|}{ Table 7: T-GARCH $(1,1)$ Results } \\
\hline \multicolumn{6}{|c|}{ Mean equation } \\
\hline & 1 & 2 & 3 & 4 & 5 \\
\hline Constant & $-0.0002(0.4069)$ & & & & \\
\hline Return (t-1) & $0.4669(0.0000)$ & $0.3749(0.0000)$ & $0.4879(0.0000)$ & $0.4764(0.0000)$ & $0.4018(0.0000)$ \\
\hline DMON & & $-0.0005(0.3635)$ & $-0.0003(0.3678)$ & $-0.0010(0.0058)$ & $-0.0007(0.0151)$ \\
\hline DTUE & & $-0.0003(0.5997)$ & $-0.0004(0.0317)$ & $-0.0023(0.0000)$ & $-0.0008(0.0011)$ \\
\hline DWED & & $0.0003(0.5083)$ & $0.0003(.2114)$ & $-0.0061(0.0667)$ & $-0.0005(0.1503)$ \\
\hline DTHUR & & $0.00008(0.8832)$ & $-0.0002(0.1229)$ & $-0.0012(0.0002)$ & $-0.0005(0.0297)$ \\
\hline DFRI & & $0.0016(0.0000)$ & $0.00010(0.6230)$ & $0.0017(0.0000)$ & $-0.0005(.00477)$ \\
\hline D2002 & & & & $0.0005(0.5191)$ & $0.0009(0.0002)$ \\
\hline D2006 & & & & $0.0012(0.0000)$ & $-0.0003(0.4360)$ \\
\hline D2011 & & & & $-0.0028(0.0000)$ & $-0.0002(0.6488)$ \\
\hline D2013 & & & & $0.0017(0.0000)$ & $0.0004(0.2488)$ \\
\hline \multicolumn{6}{|c|}{ Conditional Volatility Equation } \\
\hline Constant & $0.0005(0.0000)$ & $0.00003(0.0000)$ & $0.0000(0.0000)$ & $0.0000(0.0000)$ & $0.0000(0.0000)$ \\
\hline ARCH $(1)(\alpha 1)$ & $0.1174(0.0000)$ & $0.2215(0.0000)$ & $0.5281(0.0000)$ & $1.522(0.0000)$ & $0.3467(0.0000)$ \\
\hline$($ RESID $<0)$ ARCH $(1)(\alpha 2)$ & $0.1224(0.0003)$ & $0.1279(0.0000)$ & $0.0584(0.3110)$ & $1.4275(0.0000)$ & $-0.0303(0.5250)$ \\
\hline GARCH $(1)(\beta)$ & $-0.0055(0.0000)$ & $-0.0533(0.0000)$ & $0.1484(0.0000)$ & $0.0657(0.0000)$ & $0.1588(0.0000)$ \\
\hline DMON & & & $0.0005(0.0000)$ & & $0.0000(0.0000)$ \\
\hline DTUE & & & $-0.0001(0.000)$ & & $-0.00001(0.000)$ \\
\hline DWED & & & $0.0002(0.0000)$ & & $-0.00003(0.0000)$ \\
\hline DTHUR & & & $-0.0004(0.000)$ & & $-0.00003(0.0000)$ \\
\hline D2002 & & & & & $0.00002(0.0000)$ \\
\hline D2006 & & & & & $0.00002(0.0000)$ \\
\hline D2011 & & & & & $-0.00002(0.000)$ \\
\hline D2013 & & & & & $-0.00002(0.000)$ \\
\hline R2 & -0.26 & -0.2338 & -0.3477 & -0.3751 & -0.2525 \\
\hline Adjusted R2 & -0.2604 & -0.2357 & -0.3498 & -0.3789 & -0.2559 \\
\hline Log likelihood & 12532.62 & 12785.49 & 133332.26 & 12176.43 & 13411.03 \\
\hline Durbin - Watson & 2.9272 & 2.8911 & 3.0117 & 2.9676 & 2.9275 \\
\hline \multicolumn{6}{|c|}{ ARCH - LM TEST } \\
\hline Constant & $0.4489(0.0005)$ & $0.6085(0.0005)$ & $0.9904(0.0000)$ & $1.0045(0.0000)$ & $0.9795(0.0000)$ \\
\hline Residual squared & $0.0402(0.0215)$ & $0.0169(0.3339)$ & $0.0086(0.6225)$ & $-0.0006(0.9742)$ & $0.0131(0.4536)$ \\
\hline Observed R2 & $5.2817(0.0216)$ & $0.9342(0.3339)$ & $0.24258(0.6225)$ & $0.0011(0.9742)$ & $0.5621(0.4534)$ \\
\hline F - Statistics & $5.2870(0.0215)$ & $0.9339(0.3339)$ & $0.024245(0.6225)$ & $0.0010(0.9742)$ & $0.5619(0.4536)$ \\
\hline
\end{tabular}

\section{Concluding remarks and policy implications}

This study tested volatility of NSE-20 share index using the symmetric and asymmetric GARCH models. The daily closing prices of NSE index for fourteen years are collected and modelled using four different GARCH models that capture the volatility clustering and leverage effect for the period $2^{\text {nd }}$ January 2001 to $31^{\text {st }}$ December 2014. The different model specifications are employed in the study after confirming the unit root test, volatility clustering and ARCH effect. The results do not find evidence for volatility persistence. We also find that higher market risk provided by conditional variance will necessarily lead to higher returns. The study findings do not reveal any asymmetric effect that would provide for the presence of leverage effect. The overall conclusion of the study supports the findings of previous research studies of Karmakar (2007) Olowe (2009), Zakaria and Winker (2012) and Zivanayi and Chinzara (2012). The positive relationship between the market risk premium and market volatility is consistent with the portfolio theory. The onset of US tapering effect 
increases the daily mean returns and significantly reduces conditional volatility in daily stock returns, contrary to existing theories on the effects of depreciation on stock returns.

On the policy front, the findings of this study have a number of policy implications. First the negative daily returns and high volatility on Tuesdays and Thursdays shows the effects of open market operations mainly through the sale of government securities (treasury bills) on the daily stock returns and volatility. Therefore in the scenario whereby the date for books closure for a firm falls on a Tuesday or Thursday investors holding equity for such a firm would lose upon making the sale on such a date in addition to selling cum dividend.

The positive relationship between the market risk premium and market volatility is in tandem with the portfolio theory implying that the risk averse investors dominate the NSE. Thus in order to make the market efficient, strategies geared towards dissemination of information to shareholder and investors at large would help in reducing information asymmetry and thereby enhancing better performance for the listed firms.

The presence of volatility clustering effect indicates the volatility in daily stock returns is time varying and is not constant over time. In other words, portfolio managers and equity investors should adjust their portfolio management practice in response to the traditional risk measure of unconditional variance.

\section{References:}

Banerjee, A., \& Sarkar, S. (2006). Modelling Daily Volatility of the Indian Stock Market Using Intraday Data, Working Paper No. 588.

Black F., and Scholes M, (1973), the pricing of options and corporate liabilities, The Journal of Political Economy, 81: 637 - 654

Bollerslev, T. (1986).Generalized autoregressive conditional heteroscedasticity. Journal of Econometric, 31, 307- 327.

Chiang T. C., and Doong S.C. (2001), empirical analysis of stock returns and volatility: evidence from seven Asian stock markets based on Tar-Garch model. Review of Quantitative Finance and Accounting; 17(3):301-18.

Cifter, A. \& Ozun, A. (2008). Estimating the effects of interest rates on share prices in Turkey using a multiscale causality test. Review of Middle East Economics and Finance, 4: 68-79.

Engle, R. F. (1982).Autoregressive conditional heteroscedasticity with estimates of U.K inflation.Econometrica50, 987 - 1008

Jaffe, J. and R. Westerfield, 1985. The weekend effect in common stock returns: The international evidence, Journal of Finance, 40:433 - 454

Fama, E., and Kenneth F. (1988).Permanent and temporary components of stock prices. Journal of Political Economy, 96, 246 - 73. 
Goudarzi, H. and Ramanarayanan C.S. (2011). Modeling asymmetric volatility in the Indian stock market. International Journal of Business and Management.

Karmakar, M.2007. 'Asymmetric Volatility and Risk-Return Relationship in the Indian Stock Market.' South Asia Economic Journal, 8 (1): 99-116.

Kasman, A. and Torun, E. (2007).Long memory in the Turkish stock market return and volatility, Central Bank of the Republic of Turkey.

Kilic R., (2004) On the Long Memory Properties of Emerging Capital Markets: Evidence from Istanbul Stock Exchange, Applied Financial Economics, 14: 915-922.

Korkmaz T., Cevik E.I., Ozatac N., (2009a). Testing for Long Memory in ISE Using ARFIMA-FIGARCH Model and Structural Break Test”, International Research Journal of Finance.

Maheshchandra J.P, (2012), Long of Stock Markets of India and China, International Journal of Science and Research.

McMillan, D.G., and Thupayagale P. (2008).Efficiency of the South African equity market. Applied Financial Economics Letters, 4, 327-330.

Nelson, D. B. (1991). Conditional heteroscedasticity in asset returns: A new Approach. Econometrica, 59, 347- 370.

Oluoch and Oyugi (2012), Segmental market risk appraisal of equity investments at the Nairobi Securities Exchange, Scientific Conference Proceedings Commerce and Economic Studies Department, Jomo Kenyatta University of Agriculture and Technology, Nairobi, Kenya.

Pagan A.R., and William G.S. (1990), Alternative models for conditional stock volatility, Journal of Econometrics, 45: 267 - 290.

Poterba, J.M., and Summers L. H. (1988). Mean reversion in stock prices; evidence and implication. Journal of financial Economics, 22, 27 - 59.

Rafagut A. and Afzal M. (2012), Impact of global financial crisis on stock markets: Evidence from Pakistan and India, Journal of Business Management and Economics, (7): 275-282

Rousan, R., and Al-Khouri, R. (2005).Modelling market volatility in emerging markets in the case of daily data in Amman stock exchange 19922004.International Journal of Applied Econometrics and Quantitative Studies, 2, 99-118.

Schwert, G.W. (1989). Why does stock market volatility change over time?. Journal of Finance, 44, 1207-1239.

Zakaria, S. S. A., and P. Winker. 2012. 'Modelling Stock Market Volatility Using Univariate GARCH Models: Evidence from Sudan and Egypt. International Journal of Economics and Finance, 4 (8): 161-76.

Zivanayi, N. M., and Z. Chinzara. 2012. Risk-Return Trade-off and Behaviour of Volatility on the South African Stock Market: Evidence from 
Both Aggregate and Disaggregate Data. South African Journal of Economics, 80 (3): 345-66.

Zakoian, J. -M., 1994, Threshold heteroskedastic models, Journal of Economic Dynamics and Control, 18, 931-955. 